\title{
Prevalence of attention deficit hyperactivity disorder and other psychiatric morbidity in children with burn injuries
}

\author{
*Sathishka Wajantha Kotalawala ${ }^{1}$, Hemamali Perera $^{2}$, Sudarshi Seneviratne ${ }^{3}$, Shashie Piyumi \\ Swarnasinghe $^{4}$, Liyamini Karunaratne ${ }^{5}$, Asangi Indrachapa Kodituwakku ${ }^{6}$
}

Sri Lanka Journal of Child Health, 2018; 47(4): 326-331

\begin{abstract}
Background: Several past studies have suggested that attention deficit hyperactivity disorder (ADHD) is a risk factor for paediatric burn injuries while some have concluded that it is protective. The association has not been adequately studied in the Sri Lankan setting.
\end{abstract}

Objectives: To estimate the prevalence of ADHD and other psychiatric morbidity in children presenting with burn injuries and to compare the demographic, burn injury characteristics and past history between the children with and without ADHD.

Method: A descriptive case control study was carried out in a paediatric tertiary care hospital in Sri Lanka. The sample comprised all consecutive admissions to the burns unit, in the age range of 4 to 12 years. Swanson, Nolan and Pelham version IV (SNAP IV) was used to diagnose ADHD. Sinhala translation of the Child Behaviour Check List (CBCL) was used to assess psychiatric morbidity.

Results: Sample was 183. Prevalence of ADHD in children with burn injuries was $14.2 \%(n=26)$. Of the 26 children diagnosed with ADHD, 6 (23\%) presented with burn injury or had a past history of burn injury. This was statistically significant $(p<0.05)$. Twenty $(10.9 \%)$ children with burn injuries had other psychiatric morbidity in the

\footnotetext{
${ }^{1}$ Consultant Child and Adolescent Psychiatrist, Teaching Hospital Anuradhapura, ${ }^{2}$ Professor in Psychiatry, University of Colombo, ${ }^{3}$ Consultant Child and Adolescent Psychiatrist, Lady Ridgeway Hospital for Children, Colombo, ${ }^{4}$ Medical Officer, District General Hospital, Hambantota, ${ }^{5}$ Medical Officer, Base Hospital, Horana, ${ }^{6}$ Medical Officer, Colombo East Base Hospital, Mulleriyawa

*Correspondence: wajantha@yahoo.co.uk (Received on 03 February 2018: Accepted after revision on 16 March 2018)

The authors declare that there are no conflicts of interest

Personal funding was used for the project.

Open Access Article published under the Creative
}

Commons Attribution CC-BY (c) (i) clinical range. Internalizing problems, externalizing problems and total problems were all more common in the ADHD group than in the nonADHD group.

Conclusions: Prevalence of ADHD among children with burn injuries in this study was $14.2 \%$. Children with ADHD admitted for burn injuries had a higher risk of having past history of injuries than children without ADHD.

DOI: http://dx.doi.org/10.4038/sljch.v47i4.8594

(Keywords: Attention deficit hyperactivity disorder, burn injuries, psychiatric morbidity)

\section{Introduction}

Over half a million children are hospitalized with burn injuries every year globally ${ }^{1}$. In comparison to an adult, a given burn injury can have significant adverse reactions in a child. Children are more prone to develop hypothermia and experience a higher systemic inflammatory response than adults $^{2}$.

Attention deficit hyperactivity disorder (ADHD) is a common behaviour disorder with a childhood onset. It is estimated that $3-7 \%$ of school age children are affected by this disorder ${ }^{3}$. ADHD is characterized by hyperactivity, impulsiveness and inattention which are inappropriate to the developmental age and are observed to occur in multiple settings ${ }^{4}$. Presence of ADHD has been found to be associated with frequent burns in the paediatric population ${ }^{5}$. Underlying impulsivity and deficits in vigilance associated with ADHD are considered as causative. While some studies showed that a prevalence of ADHD among children who got treatment for burns is lower than in the general population ${ }^{6}$, many studies have shown an increased risk of burn injuries among children with $\mathrm{ADHD}^{7,8}$. The association between paediatric burn injuries and ADHD has not been adequately studied in Sri Lanka.

\section{Objectives}

The general objective was to estimate the prevalence of ADHD and other psychiatric morbidity in children presenting with burn injuries. 
The specific objectives were to compare the demographic characteristics, history of injury and burn injury characteristics between children with and without ADHD.

\section{Method}

Study design and setting: This was a descriptive case control study conducted at the Burns Unit at LRH.

Study sample: All consecutive children who got admitted with burn injuries in age range of 4-12 years were included. Children whose parents and guardians were unable to read, communicate and comprehend the Sinhala language were excluded since the assessment instruments are only validated and available in the Sinhala language. Children with pre-existing physical and intellectual disability were also excluded to avoid confounding factors as far as possible.

Sample size calculation: The sample size was calculated as 183 using the Lwanga and Lameshow, 1991 method $^{9}$.

Study Instruments: Swanson, Nolan and Pelham, version IV (SNAP IV), a standardized instrument validated for diagnosis of ADHD was used for establishing the diagnosis ${ }^{10}$. SNAP IV is in the public domain and freely accessible. Sinhala translation of this tool has been used in previous research publications in the Sri Lankan setting ${ }^{11}$. Items are based directly on the Diagnostic and Statistical Manual edition IV (DSM IV) diagnostic criteria for ADHD including subcategories and can be considered to have face validity. Sinhala translation of the Child Behaviour Check List (CBCL) was used for the assessment of psychiatric morbidity. The Sinhala translation of CBCL has been validated to measure mental health status of children in Sri Lanka ${ }^{12}$. In CBCL, behaviours that mainly impact on others are classified as externalizing problems and behaviours that have an impact mainly on the child concerned are classified as internalizing problems. A semi-structured interviewer-administered questionnaire was used to collect the demographic data, burn injury characteristics and past illness and injury history of the children.

Data collection procedure: Data was collected from the main caregiver of the child. All three study instruments were administered to the consented caregiver. Some data on burn injury characteristics were collected from clinical records. Data analysis: The data were analysed using SPSS statistics software package, version 16.0. CBCL was scored using Assessment Data Manager (ADM) Software Version 9.1.

Benefits to subjects: Children diagnosed with ADHD and other psychiatric morbidity were referred to the child psychiatry unit, LRH for further clinical assessment and follow up.

Ethics approval and consent to participate: Ethical clearance was obtained from the Ethics Review Committee of Lady Ridgeway Hospital for Children, Colombo for the study. Informed written consent of the parent(s)/ guardian(s) of the child was obtained prior to the interview. Consent forms were available in both English and Sinhala languages.

\section{Results}

A total of 183 children was admitted with burn injuries. The age range was from 4 to 12 years. Mean age was 6.48 years and median age was 6 . Majority $(62.8 \%)$ were at or below the age of six. Majority were females $(n=100,54.6 \%)$. Ninety five per cent of the children $(n=174)$ got burn injuries at their home environment. Table 1 shows the distribution of the type or source of burn injury.

Table 1: Distribution of the type or source of burn injury

\begin{tabular}{|l|c|}
\hline \multicolumn{1}{|c|}{ Type of burn } & Number (\%) \\
\hline Flame & $37(20.2)$ \\
\hline Hot water or liquid & $122(66.7)$ \\
\hline Hot object & $15(08.2)$ \\
\hline Chemical & $0(0)$ \\
\hline Steam & $01(0.5)$ \\
\hline Electric & $08(04.4)$ \\
\hline Total & $183(100)$ \\
\hline
\end{tabular}

Hot water or liquids was the main source of burn injuries followed by flame (Table 1). There were no chemical burns reported in this study sample. The extent of burns ranged from $1-45 \%$ total body surface area (TBSA) with a mean of $7.8(\mathrm{SD}=8.5)$ and a median of 5 . None of the children in the sample had a past mental health history or a history of presenting to mental health services. None of the children in the samples had a previous diagnosis of ADHD or was taking any medication for ADHD. Nineteen $(10.4 \%)$ children had a previous history of injury. Fracture $(n=6,3.3 \%)$ was the leading past injury reported. Three children $(1.6 \%)$ had previous history of burn injury. Table 2 lists the distribution of types of past injuries.

Table 2. Distribution of the types of past injuries

\begin{tabular}{|l|c|}
\hline \multicolumn{1}{|c|}{ Type of past injury } & Number (\%) \\
\hline Burns & $03(01.6)$ \\
\hline Head Injury & $01(0.5)$ \\
\hline Fracture & $06(03.3)$ \\
\hline Cut injury & $02(01.1)$ \\
\hline Aspiration & $01(0.5)$ \\
\hline Other & $06(03.3)$ \\
\hline Total & $19(10.4)$ \\
\hline
\end{tabular}


Comparison of demographic characteristics and past injury history of children with and without ADHD

Among the 26 children with ADHD, 17 (65.4\%) were males and $9(34.6 \%)$ were females. Among the non-ADHD children, $66(42 \%)$ were males and $91(58 \%)$ were females. The sex distribution difference of the two groups was statistically significant $(p<0.05)$.
Six $(23 \%)$ children with ADHD had a past history of injuries while $13(8.3 \%)$ non ADHD children had past injuries. This result is significant at $\mathrm{p}<0.05$. Table 3 compares the past injuries of children with and without ADHD. Table 4 compares the type of burn between children with and without ADHD.

Table 3: Comparison of past history of injuries of ADHD and non-ADHD children

\begin{tabular}{|l|c|c|c|}
\hline Past history of injuries & $\begin{array}{c}\text { ADHD group (n=26) } \\
\text { Number (\%) }\end{array}$ & $\begin{array}{c}\text { Non ADHD group (n=157) } \\
\text { Number (\%) }\end{array}$ & \multicolumn{1}{|c|}{ Significance } \\
\hline Present & $06(23.0)$ & $13(08.3)$ & $\begin{array}{l}\text { Chi-Square test } \\
\mathrm{df}=1 ; p=0.02, \mathrm{p}<0.05\end{array}$ \\
\hline Not present & $20(77.0)$ & $144(91.7)$ & \multicolumn{2}{|l}{${ }^{2}$} \\
\hline
\end{tabular}

Table 4: Comparison of type of burn of ADHD and non-ADHD children

\begin{tabular}{|l|c|c|c|}
\hline \multicolumn{1}{|c|}{ Type of burn } & $\begin{array}{c}\text { ADHD group (n=26) } \\
\text { Number (\%) }\end{array}$ & $\begin{array}{c}\text { Non ADHD group (n=157) } \\
\text { Number (\%) }\end{array}$ & Significance \\
\hline Flame & $08(30.8)$ & $29(18.5)$ & $\begin{array}{l}\text { Chi-square test } \\
\mathrm{df}=1 ; \mathrm{p}=0.15, \mathrm{p}>0.05\end{array}$ \\
\hline Hot water & $12(46.2)$ & $110(70.0)$ & $\begin{array}{l}\text { Chi-square test } \\
\mathrm{df}=1 ; p=0.01, \mathrm{p}<0.05\end{array}$ \\
\hline Hot Object & $02(07.7)$ & $13(08.3)$ & $*$ \\
\hline Chemical & $0(0)$ & $0(0)$ & $*$ \\
\hline Electric & $03(11.5)$ & $05(03.2)$ & $*$ \\
\hline Steam & $01(03.8)$ & $0(0)$ & $*$ \\
\hline
\end{tabular}

* Chi-square test was not performed due to inadequate numbers

One hundred and ten (77\%) children without ADHD got burn injury from hot water or liquid while $12(46.2 \%)$ children with ADHD got such burns. This result was statistically significant at $\mathrm{p}<0.05$. Eight $(30.8 \%)$ children with ADHD got burn injuries from flame while twenty nine (18.5\%) children without ADHD got such burns. This result was not statistically significant. Mean of total body surface area (TBSA) burnt in children with ADHD was $7.9 \%$ and in children without ADHD $7.8 \%$. Median TBSA was 5\% in both ADHD and non ADHD groups. Table 5 shows the prevalence of psychiatric morbidity in terms of behaviour and emotional syndromes derived from CBCL.

Table 5: Prevalence of other psychiatric morbidity among children with burn injuries

\begin{tabular}{|l|c|}
\hline \multicolumn{1}{|c|}{ Morbidity } & Number (\%) \\
\hline Withdrawn & $03(01.6)$ \\
\hline Somatic Complaints & $03(01.6)$ \\
\hline Anxious/Depressed & $05(02.7)$ \\
\hline Social Problems & $05(02.7)$ \\
\hline Thought Problems & $02(01.1)$ \\
\hline Attention Problems & $22(12.0)$ \\
\hline Delinquent Behavior & $05(02.7)$ \\
\hline Aggressive Behavior & $06(03.3)$ \\
\hline Internalizing Problems & $08(04.4)$ \\
\hline Externalizing Problems & $19(10.3)$ \\
\hline Total Problems & $\mathbf{2 0 ( 1 0 . 9 )}$ \\
\hline
\end{tabular}

Twenty (10.9\%) children with burn injuries had other psychiatry morbidity in the clinical range. Eight (4.4\%) had internalizing disorders and 19 $(10.3 \%)$ had externalizing disorders in the clinical range. Attention problems was the leading syndrome $(n=11,6 \%)$. Attention problems were the commonest $(\mathrm{n}=18,69.2 \%)$ psychiatric morbidity among ADHD group as well as non-ADHD group $(\mathrm{n}=4,2.5 \%)$. Internalizing problems, externalizing problems and total problems were all more common in the ADHD group than in the nonADHD group. Significance of this finding was not estimated statistically due to the smaller numbers in the subgroups.

\section{Discussion}

The prevalence of ADHD in the general population is generally accepted as around $5 \%$ in most cultures $^{4}$. In Sri Lanka, a similar prevalence of $5.1 \%$ has been reported in children attending medical and surgical outpatient clinics ${ }^{13}$. The main finding of the present study is the prevalence of ADHD in children with burn injuries as $14.2 \%$, which is three times higher than the expected prevalence of ADHD in the general population. The present study also revealed that $10.9 \%$ had other psychiatry morbidity in the clinical range, $4.4 \%$ had internalizing disorders and $10.3 \%$ of children had externalizing disorders at the clinical 
range. The prevalence found in current study is comparable with a study done in USA which concluded the prevalence of ADHD in a population of children with burn injuries as $13 \%{ }^{14}$. The prevalence found in the present study is also similar to the prevalence of ADHD found in children presenting with self-inserted nasal and aural foreign bodies in the Sri Lankan setting. A prevalence of $14.3 \%$ for ADHD was identified in this $s$ tudy ${ }^{15}$. Another study done in the same tertiary care hospital in Sri Lanka revealed the prevalence of ADHD among children seen at the Accident Service with unintentional injuries as $18 \%{ }^{11}$. However the previous studies mentioned above have not studied the other psychiatric morbidity as the present study.

According to the literature, burns more commonly occur in children below the age of five years ${ }^{16,17}$. In the current study sample, $62.8 \%$ of the children who presented with burn injuries are at or below the age of six, confirming the above findings in the Sri Lankan setting. However the other previous study done in Sri Lanka at Accident service revealed a higher mean age of 8.5 years in children who presented with unintentional injuries ${ }^{11}$. According to most previous studies, boys have a higher incidence of burn injuries, accounting for $60-70 \% 0^{16,17}$. In contrast to that, the present study sample consisted of $54.6 \%$ of females. This is compatible with the sample of children presenting with self-inserted nasal and aural foreign bodies $\left(51 \%\right.$ of females) in the previous study ${ }^{15}$. However, $75 \%$ were males, in the sample presenting with unintentional injuries to accident service in the previous study ${ }^{11}$.

According to the world literature, the vast majority of paediatric burn injuries are reported to have occurred at home ${ }^{12}$. The current study also confirmed the above finding as $95 \%$ of the study sample got burn injuries in their home environment.

According to the current study, hot water or liquids were the main source $(66.6 \%)$ of burn injuries followed by flame $(20.2 \%)$. This is compatible with a population-based study carried out in a rural area in of the USA which revealed that children aged 0 4 years were most likely to be injured by scald and hot-object contacts and older children and young adults aged 5-24 years had the highest populationbased rates of flame ${ }^{18}$.

Comparison of ADHD and non-ADHD groups in terms of their past history of injuries, revealed some important findings. Twenty three percent of children who presented with burn injury and who met the diagnosis of ADHD, had a past history of injuries which was statistically significant. This result may indicate that children presenting with recurrent injuries of various nature have a higher possibility of having ADHD, which needs to be explored further. The previous study done in Sri Lanka in the accident service also revealed that children with ADHD were more likely to have history of repeated injuries than children without ADHD (44.4\% versus 23.4\%) who presented with unintentional injuries.

Comparison of the source of burn between ADHD and non ADHD groups in the current study revealed that non ADHD children were more likely to get hot water or liquid burns than ADHD group. This result seems to be due to children with ADHD tending to get more flame burns than children without ADHD. However a previous study done in USA revealed, that children with ADHD are more likely to suffer a thermal or chemical burn injury than a flame-related injury. However this previous study compared children already diagnosed with ADHD and parents and caregivers were aware of the diagnosis ${ }^{14}$. Therefore, caregivers for children with ADHD are expected to be aware of the dangers of open flames and matches around these children and would have taken precautions to prevent them from open fires. However in the present study no child was previously diagnosed with ADHD and parents would not have had much awareness around the possible risks associated with ADHD.

In the current study, the comparison of total body surface area (TBSA) burnt in ADHD and non ADHD groups was largely similar in mean and median. This is in contrast to a previous study done in United States in which found that children with ADHD sustained more severe TBSA burns (10\% versus $5 \%$ median TBSA, $\mathrm{P}=0.03$ ) than children without $\mathrm{ADHD}^{14}$.

Vast majority of studies found in the literature have focused on psychiatric morbidity or psychological consequences following burn or other injuries in children $^{19,20}$. The literature on association of psychiatric morbidity during or prior to burn or other injuries are scarce. The present study also focused on pre-burn psychiatric morbidity and it revealed that $10.9 \%$ of children had psychiatry morbidity in the clinical range. Prevalence of externalizing problems (10.3\%) was more than double the prevalence of internalizing problems $(4.4 \%)$.

This is the first study conducted in Sri Lanka which explored the association between burn injuries and 
ADHD in children. The current study also compared the demographic characteristics, past illness and injury history, burn type and intensity of the burn injury in terms of total body surface area affected, between ADHD and non ADHD groups identified by the same study. In comparison to most of the studies done elsewhere on this topic, the current study explored other psychiatric morbidities in addition to ADHD.

There are several limitations of the study. Diagnosis of ADHD was made primarily using SNAP IV instrument. Although it has been validated for diagnosis of ADHD, it is not validated for Sinhala language and it is not the gold standard method to diagnose ADHD. This study was hospital based rather than population based. Therefore, only severely burnt children who needed in-ward treatment were included in the study. Hence, the results cannot be generalized as true prevalence of ADHD in burns. The present study used instruments which were in the Sinhala language. Therefore children whose parents and guardians were not able to read, communicate and comprehend Sinhala language were excluded from the study. This can also reduce the generalizability of the results as it did not satisfactorily represent the other ethnic groups at hospital population level.

\section{Conclusions}

Prevalence of ADHD among children with burn injuries was three times higher than the expected prevalence of ADHD in the general population. Children with ADHD who were admitted for burn injuries had a significantly higher risk of having past history for injuries than children without ADHD. Children without ADHD had a positive association with getting burn injury from hot water or liquid compared to children with ADHD. Psychiatric morbidity in terms of internal problems, external problems and total problems were all more common in ADHD group than in non-ADHD group which need to be explored further.

\section{References}

1. Burd A, Yuen C. A global study of hospitalized paediatric burn patients. Burns 2005; 31(3): 432-8. https://doi.org/10.1016/j.burns.2005.02.01 6

PMid: 15896504

2. Fenlon S, Nene S. Burns in Children. Continuing Education in Anaesthesia Critical Care and Pain 2007; 7(3):76-80. https://doi.org/10.1093/bjaceaccp/mkm01 1
3. Barkley R. What is attentiondeficit/hyperactivity disorder? In: Taking Charge of ADHD: The Complete, Authoritative Guide for Parents. Rev Ed. New York: The Guilford Press; 2000. pp. 19-48.

4. Diagnostic and Statistical Manual of Mental Disorders 5th Edition (DSM-5), American Psychiatric Association 2013.

5. Kessler RC, Adler L, Barkley R, Biederman J, Conners CK, Demler O, et al. The prevalence and correlates of adult ADHD in the United States: Results from the National Comorbidity Survey Replication. American Journal of Psychiatry 2006; 163:716-23. https://doi.org/10.1176/ajp.2006.163.4.71 6

PMid: 16585449 PMCid: PMC2859678

6. Thomas CR, Ayoub M, Rosenberg L, Robert RS, Meyer WJ. Attention deficit hyperactivity disorder \& pediatric burn injury: a preliminary retrospective study. Burns 2004; 30: 221-3. https://doi.org/10.1016/j.burns.2003.10.01 3

PMid: 15082347

7. Badger K, Anderson L, Kegan RJ. Attention deficit-hyperactivity disorder in children with burn injuries. Journal of Burn Care and Research 2008; 29: 724-9. https://doi.org/10.1097/BCR.0b013e31818 480e1

PMid: 18695621

8. Ghanizadeh A. Small burns among outpatient children and adolescents with attention deficit hyperactivity disorder. Burns 2008; 34: 546-8. https://doi.org/10.1016/j.burns.2007.07.01 5

PMid: 17959315

9. Lwanga SK, Lemeshow S. Sample size determination in health studies: a practical manual. Geneva: World Health Organisation; 1991

PMCid: PMC2393240

10. Bayat A, Ramaiah R, Bhananker SM. Analgesia and sedation for children undergoing burn wound care. Expert 
Review of Neurotherapeutics 2010; 10:1747-59.

https://doi.org/10.1586/ern.10.158

PMid: 20977331

11. Perera H, Jeewandra KC, Jayasuriya N, Dias R. Prevalence of attention deficit hyperactivity disorder in children with unintentional injuries Sri Lanka Journal of Child Health 2012; 41(1): 20-3.

12. Dissanaike S, Rahimi M. Epidemiology of burn injuries: highlighting cultural and socio-demographic aspects. International Review of Psychiatry 2009; 21(6): 505-11. https://doi.org/10.3109/095402609033408 65

PMid: 19919203

13. Badger $\mathrm{K}$, Anderson L, Kagan RJ. Attention deficit-hyperactivity disorder in children with burn injuries. Journal of Burn Care \& Research 2008; 29:724-9. https://doi.org/10.1097/BCR.0b013e31818 480e1

PMid: 18695621

14. Mangusa RS, Bergmanb D, Zieger M, Colemanb JJ. Burn injuries in children with attention-deficit/hyperactivity disorder. Burns 2004; 30:148-50.

https://doi.org/10.1016/j.burns.2003.09.02 0

PMid: 15019122

15. Perera H, Fernando SM, Yasawardena ADKSN, Karunarathne I. Prevalence of attention deficit hyperactivity disorder (ADHD) in children presenting with selfinserted nasal and aural foreign bodies. International Journal of Pediatric Otorhinolaryngology 2009; 73:1362-4. https://doi.org/10.1016/j.ijporl.2009.06.01 1

PMid: 19616315

16. Drago DA. Kitchen scalds and thermal burns in children five years and younger. Pediatrics 2005; 115(1). Available from: http://pediatrics.aappublications.org/conte $\mathrm{nt} / 115 / 1 / 10$ ?download $=$ true https://doi.org/10.1542/peds.2004-0249 PMid: 15629975
17. Kai-Yang L, Zhao-Fan X, Luo-Man Z, YiTao J, Tao T, Wei W, et al. Epidemiology of paediatric burns requiring hospitalization in China: A literature review of retrospective studies. Pediatrics 2008; 122(1): 132-42.

https://doi.org/10.1542/peds.2007-1567

PMid: 18595996

18. Wibbenmeyer LA, Amelon MJ, Torner JC, et al. Populated-based assessment of burn injury in southern Iowa: identification of children and young-adult at-risk groups and behaviors. Journal of Burn Care and Rehabilitation 2003; 24:192-202.

https://doi.org/10.1097/01.BCR.00000759 68.37894.7C

PMid: 14501412

19. Davydow DS, Richardson LP, Zatzick DF. Psychiatric morbidity in paediatric critical illness survivors. A comprehensive review of the literature. Archives of Pediatrics and Adolescent Medicine 2010; 164(4): 377-85.

https://doi.org/10.1001/archpediatrics.201 0.10

PMid: 20368492 PMCid: PMC2881634

20. Rees G, Gledhill J, Garralda ME, Nadel S. Psychiatric outcome following paediatric intensive care unit (PICU) admission: a cohort study. Intensive Care Medicine 2004, 30(8): 1607-14. https://doi.org/10.1007/s00134-004-23109

PMid: 15112035 